This item was submitted to Loughborough's Research Repository by the author.

Items in Figshare are protected by copyright, with all rights reserved, unless otherwise indicated.

\title{
Planning and implementing field operational tests of intelligent transport systems: a checklist derived from the EC FESTA project
}

\section{PLEASE CITE THE PUBLISHED VERSION}

\section{PUBLISHER}

(C) The Institution of Engineering and Technology

\section{VERSION}

AM (Accepted Manuscript)

\section{LICENCE}

CC BY-NC-ND 4.0

\section{REPOSITORY RECORD}

Regan, Megan A., and John H. Richardson. 2019. "Planning and Implementing Field Operational Tests of Intelligent Transport Systems: A Checklist Derived from the EC FESTA Project". figshare.

https://hdl.handle.net/2134/5396. 
This item was submitted to Loughborough's Institutional Repository (https://dspace.lboro.ac.uk/) by the author and is made available under the following Creative Commons Licence conditions.

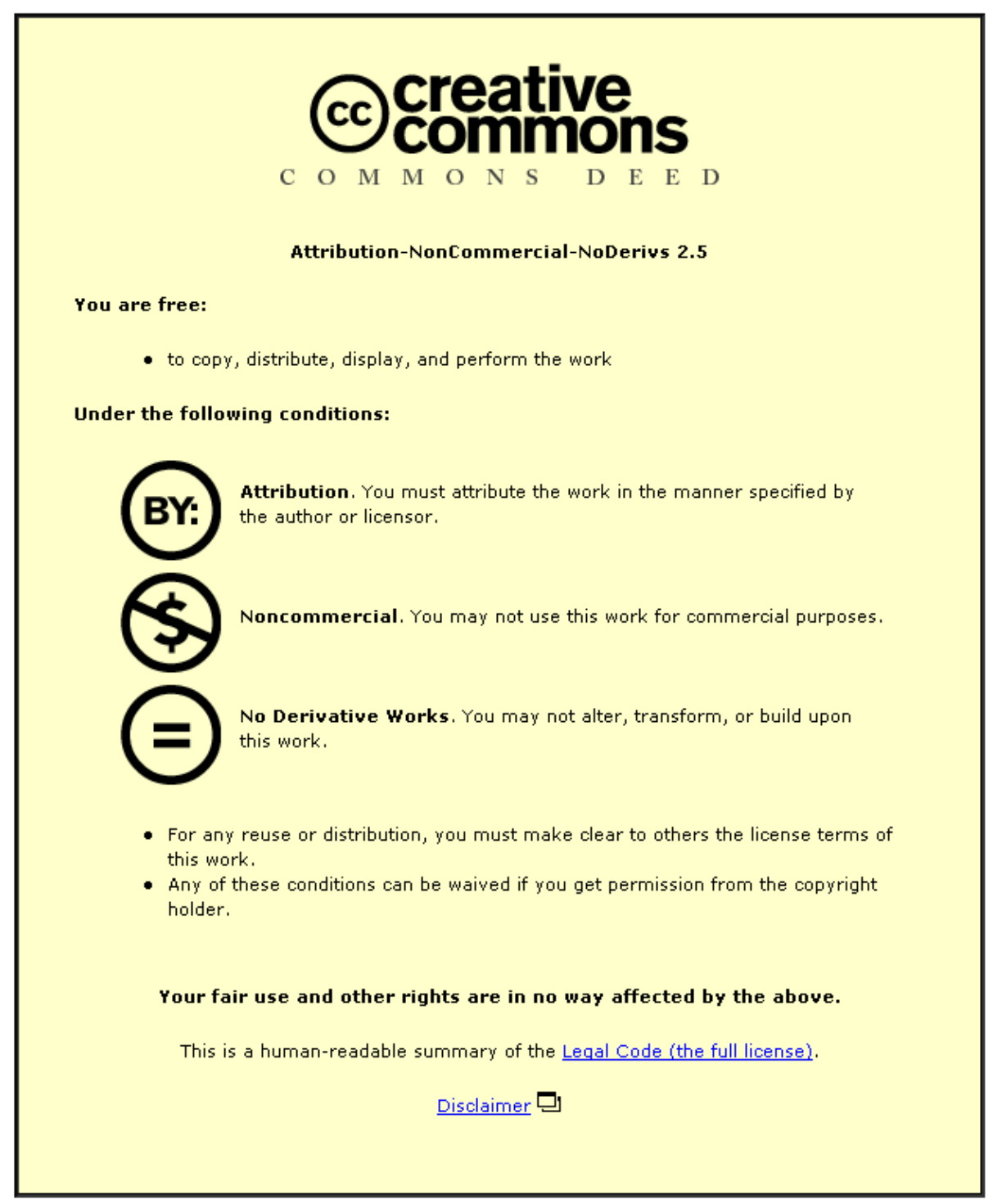

For the full text of this licence, please go to: http://creativecommons.org/licenses/by-nc-nd/2.5/ 
This paper is a postprint of a paper submitted to and accepted for publication in IET Intelligent Transport Systems and is subject to Institution of Engineering and Technology Copyright.

The copy of record is available at IET Digital Library.

\title{
Planning and Implementing Field Operational
}

\section{Tests of Intelligent Transport Systems: a}

\section{Checklist derived from the EC FESTA Project}

\author{
M.A. Regan ${ }^{1}$ and J.H Richardson ${ }^{2}$ \\ ${ }^{1}$ Institut National de Recherche sur les Transports et leur Sécurité (INRETS), Avenue François \\ Mitterrand, F-69675 BRON CEDEX, France. michael.regan@inrets.fr \\ ${ }^{2}$ ESRI, Loughborough University, Loughborough. LE11 3TU. UK. j.h.richardson@lboro.ac.uk
}

\begin{abstract}
:
To date, the main focus of ITS research programs has been on technology development and proof of concept, rather than on understanding the implications of system implementation. Improved knowledge is needed about the ways in which drivers use intelligent transport systems, their short- and long-term effects, and how system performance can be optimized. The Field Operational Test, or FOT, is a sophisticated evaluation method that can be used to answer these and other critical questions, and to stimulate market acceptance and demand for ITS. Whilst the large-scale FOTs conducted to date have yielded important insights into both the positive and potentially negative impacts of ITS, there is considerable scope for improving the design and implementation of FOTs. There are many advantages in doing so. This paper outlines, in the form of a checklist, the critical steps, and considerations, involved in successfully planning and implementing a Field Operational Test, drawing on work undertaken in the EC-funded FESTA (Field opErational TeSt support Action) project.
\end{abstract}




\section{Introduction}

Intelligent Transport Systems (ITS) employ information and communication technologies to enhance the safety, efficiency, user- and environmental-friendliness of the transport system. Essentially, they are information and communication technologies (ICT) applied to transport. Although the idea of using ICT to improve transport systems emerged during the early 1950s, it is only in the last 20 years that systems technically capable of meeting the expectations of stakeholders have been developed (1). In Europe, the European Commission (EC) has funded many ITS-related research and development projects during this period, under four European research framework programs. Comparable research programs have also been funded and undertaken in Japan and the United States. The main focus of these research programs has been on technology development and proof of concept, rather than on establishing the implications of system implementation (2). While demonstrations have tested the technical and functional behaviour of systems, they have often been constrained by controlled conditions and a limited scale, due to both a scarcity of equipment and restrictions on being able to operate pre-production systems in real traffic environments (2). As Zobel (2) points out (p. 16), this situation has created a need for improved knowledge of some key questions that are crucial for faster market implementation of ITS technologies: “..the way drivers use intelligent systems, what their short and long term effects are, and how system performance could be further improved”.

The Field Operational Test (FOT) is a sophisticated evaluation method that can be used to answer these sorts of questions. An FOT is "a study undertaken to evaluate a function, or functions, under normal operating conditions in environments typically encountered by the host vehicle(s) using quasi-experimental methods” (3, p.1). Basically, it is a large-scale, quasi experimental field evaluation of an ITS technology or function. An FOT allows for the rigorous assessment of ITS-based systems in their intended environment by their intended users, on a scale, and with a duration, sufficient enough for statistically robust conclusions to be drawn. FOTs can be designed to address many issues (2): to validate system effectiveness in 
enhancing safer, cleaner and more efficient transport; analyse driver behaviour and user acceptance of systems; analyse and assess system impact; improve awareness of ITS potential and create market acceptance and demand; and derive technical data for system design, re-design and product development. Further, the 'real road' assessment context is readily understood by potential users, system developers, manufacturers and the regulatory authorities, and the extensive data collected can support a wide range of post-hoc investigations by researchers, for many years.

\section{Previous FOT Activity}

There are significant technical, organisational and logistic challenges in planning, preparing for and implementing a large-scale FOT - and there is a step change increase in resource requirements compared with traditional, smaller scale, demonstrations. Despite this, there has been a surge in FOT activity during the last decade.

In the USA, for example, the University of Michigan Transportation Research Institute (UMTRI) undertook in the late 1990s a pioneering assessment of the impact of intelligent cruise control (ICC) usage on passenger car drivers (4). A total of 108 drivers drove 10 equipped vehicles as their own personal cars for periods of 2 to 5 weeks, completing some 35,000 miles of recorded driving. This was succeeded by an evaluation of autonomous collision avoidance systems (ACAS) in conjunction with General Motors (5). A sample of drivers using 11 equipped vehicles completed some 137,000 miles of closely monitored driving over a 12 month period. These initial FOT activities were significantly extended through the US Department of Transport's (DoT's) Intelligent Vehicle Initiative (IVI); a programme of FOTs undertaken with truck manufacturers, their suppliers and the haulage industry whose aim was to assess the safety benefits of a range of intelligent vehicle safety systems (IVSS). The programme assessed the value of collision warning, lane departure warning, intelligent braking, ACC and roll stability warning systems within a strong cost benefit analysis methodology. 
Large-scale FOTs have also been undertaken in Europe, notably in Sweden, France the Netherlands and the UK. The then Swedish National Road Authority (SNRA) implemented an extensive FOT to evaluate the effects of Intelligent Speed Adaptation (ISA), a system that automatically limits vehicle speed to the posted limit or warns the driver when it is exceeded. Several variants of the system were evaluated, in over 4,500 vehicles in 4 test sites. (6). In France, the Ministry of Transport sponsored the LAVIA (Limiteur s'Adaptant à la VItesse Autorisée) project, to assess ISA in a test site south of Paris. One hundred volunteer drivers used 20 vehicles to assess three variants of ISA: advisory, voluntary and mandatory (7). In 1999, the Netherlands Ministry of Transport also conducted an ISA assessment in the town of Tilburg. The FOT involved 20 passenger cars and some 120 drivers experiencing ISA over an 8-week period (8). Finally, in the UK the Department for Transport sponsored ISA trials undertaken by the University of Leeds and MIRA Ltd (9). These trials involved the use of 20 instrumented vehicles by 79 volunteer drivers over a period of 24 weeks each. Smaller-scale ISA FOTs have also been conducted in Finland and Belgium (10). Interestingly, the focus of FOTs in Europe has been almost exclusively on ISA.

FOTs have also been carried out in the southern hemisphere, notably in Japan and Australia. In Japan, vehicle manufacturers tend to use the home market itself as a large-scale FOT for the early evaluation of new systems, and the FOT is seen as an integral part of the research and development chain (2). In Australia, FOTs have been less common. Notable, however, is the Transport Accident Commission (TAC) SafeCar project, which evaluated, alone and in combination, three ITS technologies: ISA, headway warning and seatbelt reminders. In that study, 23 fleet car drivers completed at least 16,000 kilometres of driving each in 15 test vehicles (11). Interestingly the study was funded by an insurance company (the TAC).

This brief summary has highlighted some of the major FOTs conducted to date. Many other evaluation studies have been undertaken, albeit on a smaller scale. If the definition of a FOT is broadened to include the assessment of intelligent infrastructure (e.g. variable message signs), then the number of FOTs is very much greater. Whilst the large-scale FOTs conducted to date have yielded important insights into both the positive and potentially negative impacts of ITS, there has been considerable variation between studies in the aims, objectives and approaches undertaken. This diversity can make it difficult to make robust 
comparisons between the results obtained. If, for example, there is inconsistency in the outcomes of ISA FOTs undertaken in two countries, is this because of technical differences in the systems evaluated or because of critical differences in the many significant study design-related variables (e.g., driver experience and training, test duration, traffic environment, data recording and analysis equipment and protocols, etc)? The ability to draw, with confidence, conclusions from the outcomes of different FOTs requires a degree of harmonisation in methodology. Furthermore, while the studies described have been major undertakings at the regional and state level, they are relatively modest when considered at a global level. There is considerable diversity in conditions across, for example, Europe or North America (market, traffic conditions, geography, climate etc) and FOTs involving multiple samples of drivers and thousands of vehicles are necessary in order to achieve statistically reliable results that are representative of the subject populations.

\section{Future FOT Activity in Europe}

As noted, the EC has played a major role in supporting the development of ITS in Europe over the past 20 years, with ITS being seen as a critical technology in the achievement of the Commission's goals relating to improvements in transport safety, mobility, efficiency and environmental sustainability. Under the various R\&D Framework Programmes the Commission has supported a wide range of ITS technology development and demonstration projects. However, it was only following the adoption of the Intelligent Car Initiative in 2006, and the associated commitment to implement ITS across Europe, that calls for major FOT evaluations became insistent.

The seventh European research framework program (FP7) will fund EC-supported research and development during 2007-2013, and FOTs will be among the major activities undertaken within ICT priority challenge 6 (ICT for Mobility, Environmental Sustainability and Energy). The EC has planned FOT deployment in 3 successive phases, with the aim of ensuring compatibility across Europe of data collected, data analysed, interoperability of solutions, and a common methodological framework (,2): an 
initial preparation activity to develop a common methodological approach for designing, running and evaluating FOTs; several large-scale FOTs that address mature or close-to-market technologies; and a third phase that will build on the outcomes of the first two phases and investigate cooperative ITS technologies.

After a call for proposals, and their subsequent review, the EC approved support for three projects within this FOT deployment path: FESTA (Field opErational TeSt support Action), a six-month, Phase 1, support action, and two major Phase 2 FOTs - EuroFOT and TeleFOT. FESTA, which is the focus of the remainder of this paper, has developed a common methodology. EuroFOT will assess advanced driver assistance systems (ADAS) and active safety systems, while TeleFOT will assess the issues of safe installation and use in vehicles of nomadic and aftermarket devices. These projects will commence later in 2008.

\section{The EC FESTA Project}

The FESTA project, completed in August 2008, produced as its major deliverable a handbook of best practice for the design and implementation of FOTs in Europe (3). The Handbook describes, in 9 chapters, the key issues to be addressed: the steps in planning and running a FOT (Chapter 2 and Annex B); legal and ethical issues (Chapter 3); the selection of functions to be tested, and definition of use cases, research questions and hypotheses relating to those functions (Chapter 4); the selection of performance measures and indicators for testing research hypotheses (Chapter 5); experimental procedures, including participant selection, study design, study environment and pilot testing (Chapter 6); guidelines on data acquisition (Chapter 7); guidelines for databases and analysis tools (Chapter 8); data analysis and modeling (Chapter 9); and determining socio-economic impact (Chapter 10).

Chapter 2 of the handbook, and in particular Annex B (FOT Implementation Plan), are the focus of the remainder of this paper. The FOT Implementation Plan is described in the following section.

\section{The FOT Implementation Plan}




\subsection{Purpose}

The FOT Implementation Plan, or FOTIP, is intended to serve primarily as a checklist for planning and running FOTs. It serves several sub-purposes: to highlight the main activities and tasks that would normally be undertaken in successfully completing a FOT; to ensure that, in running a FOT, researchers and support teams are aware of critical issues that influence the success of the FOT; by drawing on the experiences of previous FOTs, to highlight the "dos" and "don'ts" of running a FOT; and to provide a consistent framework for planning, running and decommissioning FOTs.

As noted, the FOTIP appears as Annexe B to the FESTA Handbook, in the form of a table that spans 28 pages. The FOTIP, and its development, are. described below.

\subsection{Development of the FOTIP}

The content of the FOT Implementation Plan derives from several research activities undertaken within Work Package 2.5 of the FESTA project: (a) a review of the literature on previous FOTs undertaken in different parts of the world: the United States and Canada; the Asia-Pacific region (including Japan and Australia); Europe; and Scandinavia. This included reference, where possible, to FOT project plans, internal reports, meeting minutes and related documents; (b) a one-day international workshop with FOT experts who had previously conducted FOTs in Australia, Europe and the United States. This activity, along with the outputs of the literature reviews, identified critical activities and tasks necessary for successfully conducting FOTs, as well as the practical “dos” and "don'ts” of carrying out FOTs; (c) an international teleconference with experts with experience in conducting FOTs and so called "naturalistic driving studies". This augmented the information derived from the workshop; (d) written feedback from FOT experts, who commented on an earlier draft of the FOT Implementation Plan; and (e) internal consultation with other members of the FESTA consortium, to identify critical scientific, technical and administrative activities arising from other FESTA research activities undertaken in developing other chapters of the FESTA Handbook.

\subsection{Description of the FOTIP}


The original FOTIP, developed within the FESTA project, is presented in the form of a table with five column headings. These are labeled, from left to right, “Activities”, “Tasks and Sub-Tasks”, “Person/Organisation Responsible for Activity”, “Critical Considerations (the “dos” and “don’ts”) ” and "General Advice” (3). The original table is a 28-page document that is too long to reproduce in this paper. Instead, we have summarized and distilled here the critical information deriving from the original table. This is presented in Table 1, Activities, tasks and critical considerations in planning and executing an FOT (see below).

The table contains three columns. Column 1 (labeled “Activities”) lists the 22 key activities that were identified in the FESTA project as being necessary in successfully planning, running and decommissioning a FOT. Column 2 (labeled “Tasks”) lists the 161 Tasks that were identified as being necessary to directly support these Activities. Essentially, this column contains a series of action statements - “do this”; “do that”; etc. Column 3 (labeled Critical considerations (the “dos” and “don’ts”)) summarizes the more important advice relating to the planning, design and setting up of a FOT.

\section{<Insert Table 1 about here>}

\section{Discussion}

Previous sections of this paper have defined what is meant by an FOT, what they can achieve, past, current and future anticipated FOT activity, especially within Europe, and the outcomes of the EC-funded FESTA project - with a particular focus on the development of the FOT Implementation Plan. Although the two tables describing the FOTIP are self-explanatory, and contain a lot of information, there are some general comments that can be made about them. 
The FOTIP is not intended to be prescriptive, but rather to serve as a generic guide in conducting FOTs. There are many political, economic, scientific, logistical and other practical issues that ultimately define the nature and sequencing of activities that characterize them.

The FOTIP describes what needs to be done, and approximately when, in running a successful FOT. Relevant chapters in the FESTA Handbook describe in detail why these activities are necessary and how they can be accomplished.

Significant previous FOTs that have failed to deliver their anticipated outcomes, have done so primarily because of failures to anticipate problems that compromised their successful execution. The FOTIP attempts to map out all known critical issues that need to be taken into account in planning and undertaking a successful FOT.

The history of FOTs suggests that no two will be the same, and that there often are many unforeseen tasks that arise during their lifecycle. The list of Tasks contained in the FOTIP is not, therefore, exhaustive. It is based on the collective wisdom of those that have been involved in planning and running previous FOTs. There may be specific requirements for future FOTs conducted in Europe that will need to be decided on a case-by-case basis.

There is no one way of conducting a successful FOT. The review of the literature on FOTs conducted during the FESTA project revealed that many different approaches have been taken in planning, running, analysing and decommissioning FOTs. The FOTIP draws together procedural activities that are most common to the known FOTs that have been conducted, and the collective wisdom of those who conducted them. The FOTIP can be considered a skeleton into which the requirements of particular FOTs can be melded.

The FOT Implementation Plan is relevant both to FOTs in which the ADAS and IVIS systems to be evaluated already exist as production systems in vehicles, and to studies in which the systems to be evaluated must be chosen by the FOT project team, purchased or developed, and installed (e.g., as in 11). Whilst the former scenario is most likely to be the case for the large-scale FOTs to be run in Europe, the latter one may be more likely in other continents and countries in which FOTs are only starting to emerge. 
The FOT Implementation Plan provides only a general guide to the sequence in which Activities and Tasks should be performed. Some need to happen early in the project and others at the end. Some need to immediately precede others. Other tasks need to proceed concurrently with others. Decisions about the scheduling of Activities, Tasks and Sub-Tasks are ultimately the responsibility of the FOT Project Manager. The FESTA Handbook list the 22 Activities identified in the FOTIP, and highlights the main dependencies that exist between them. Within Activities, it is up to the FOT Project manager to further decide which Tasks should proceed sequentially and in parallel.

Some of the major Tasks listed in the FOTIP (e. g. "recruit participants”, within the Activity "Run FOT”) are given only a one-line description and, as such, may appear to be down played in the plan. A judgement had to be made about how much detail to include in the FOTIP. Where such one-liners exist, this is because either the Task in question is one that most researchers would normally be familiar with (e. g., recruiting study participants) or because the Sub-Tasks involved are described in detail in relevant Chapters of the FESTA Handbook..

Some general advice can be offered to those using the FOTIP: read through the FOTIP before starting to plan a FOT; use the FOTIP as a checklist both for guiding the planning, design and running of the FOT, and as a quality control mechanism for ensuring during the study that nothing critical has been forgotten; ideally read the FOTIP in conjunction with relevant chapters of the FESTA Handbook; and, if desired, use the FOTIP as the basis for the development of GANTT charts and other project management tools.

The user-centred design of any tool or product critically involves evaluation - and, as a result of feedback from evaluation, the refinement of the tool or product. The FOTIP described here, and indeed the FESTA handbook, are products - but they have not been tested for usability, and there is no direct mechanism by which feedback from FOTs that use the FOTIP can be used to refine them. The European Commission has, however, funded under FP7 the two-year FOTNET project, which will create among other things a networking platform for promoting adoption of the FESTA results and a common methodology. This may provide a forum for user feedback that can be used to refine the FOTIP. 


\section{Conclusion}

This paper has outlined the critical steps, and considerations, involved in successfully planning and implementing a FOT, drawing on work undertaken in the EC-funded FESTA project. In it, the authors have distilled the most important information contained in Chapter 2 and Annex B of the FESTA Handbook. The FESTA Handbook contains much more detailed information on each of these activities and tasks. Anyone intending to plan and implement a FOT is therefore advised to read that document as the primary reference source.

\section{Acknowledgements}

The work reported here was funded by the European Commission DG Information Society and Media in the 7th Framework Program. The authors are grateful to Fabrizio Minarini, from the EC, for his support.

The following members of the FESTA Work Package 2.5 project team provided scientific and technical input used to develop the FOT Implementation Plan: Virpi Anttila; Maxime Flament; Stig Franzen; Tom Gasser; Christard Gelau; Magnus Hjalmdahl; Katja Kircher; Sylvain Lassarre; Petri Mononen; Pirkko Rama; Farida Saad; and Ronald Schindhelm. We thank also for their input the following members of the FESTA consortium: Luisa Andreone; Vincent Blervaque; Gianfranco Burzio; Oliver Carsten; Marco Dozza; Magnus Hjalmdahl; Riku Kotiranta; Friedemann Kuhn; Samantha Jamson; Kerry Malone; and TrentVictor.

We are grateful to the following external experts for their valuable insights: Jim Sayer of UMTRI, Charlie Klauer of VTTI, Tom Triggs, Kristie Young, Eve Mitsopoulos-Rubens, Nebojsa Tomasevic and Karen Stephan of MUARC, Harri Peltola of VTT and Riku Kotiranta of Chalmers University of Technology. 


\section{References}

1. ETSC. Intelligent Transport Systems and Road Safety. Brussels, Belgium: European Transport Safety Council; 1999.

2. Zobel, R.. Intelligent systems for better mobility: Bringing to market. Intelligent Transport Systems Society Newsletter; 10 (1), January 2008, pp 16-18.

3. Centro Ricerche Fiat. FESTA Handbook (2008; Version 2). Turin, Italy: Centro Ricerche Fiat (Available at http://www.its.leeds.ac.uk/festa/)

4. Fancher, P., Ervin, R., Sayer, J., Hagan, M., Bogard, S., Bareket, Z., Mefford, M. \& Haugen, J. Intelligent cruise control field operational test. Final report. Volume I: Technical report. UMTRI-9817; DOT/HS 808 849; University of Michigan, Ann Arbor, Transportation Research Institute; 1998.

5. Ervin, R. D., Sayer, J., LeBlanc, D., Bogard, S., Mefford, M., Hagan, M., Bareket, Z. \& Winkler, C. Automotive collision avoidance system field operational test methodology and results, volume 1 : technical report; UMTRI-2005-7-1; DOT HS 809 900; University of Michigan, Ann Arbor, Transportation Research Institute; 2005.

6. Swedish National Road Administration. Results of the world's largest ISA trial, [Brochure], Swedish National Road Administration, Borlänge, Sweden; 2002.

7. Ehrlich, J.. Carnet de route du Lavia - Limiteur s’adaptant à la vitesse autorisée. Paris, France: Institut National de Recherche sur les Transports et leur Sécurité ; 2006.

8. Besseling, H., \& van Boxtel, A.. Intelligent speed adaptation: results of the Dutch ISA Tilburg trial. Ministry of Transport, Public Works and Watermanagement, Directorate General of Public Works and watermanagement, Transportation Research Centre, Rotterdam, The Netherlands; 2002.

9. Carsten, O., Fowkes, M., Lai, F., Chorlton, K., Jamson, S., Tate, F. and Simpkin, B. Final Report. Intelligent Speed Adaptation,.. Institute for Transport Studies, University of Leeds, Leeds, United Kingdom;. 2008. Chapter 3, pp 4-26 
10. Vlassenroot, S., Broekx, S., De Mol, J., Int Panis, L., Brijs, T. and Wets, G. Driving with intelligent speed adaptation: Final results of the Belgian ISA-trial. Transportation Research, Part A: Policy and Practice; 2007. 41 (3), 267-279

11. Regan, M., Young, K., Triggs, T., Tomasevic, N., Mitsopoulos, E., Tierney, P., Healey, D., Tingvall, C. \& Stephan, K. Impact on driving performance of Intelligent Speed Adaptation, Following Distance Warning and Seatbelt Reminder Systems: Key findings from the TAC SafeCar project. IEE Proceedings Intelligent Transport Systems; 2006. 53, (1), pp 51-62 
Table 1: Activities, tasks and critical considerations in planning and executing an FOT

\begin{tabular}{|c|c|c|}
\hline Activities & Tasks & Critical Considerations (the “dos” and “don'ts”) \\
\hline $\begin{array}{l}1 . \\
\text { Convene FOT } \\
\text { teams and people }\end{array}$ & 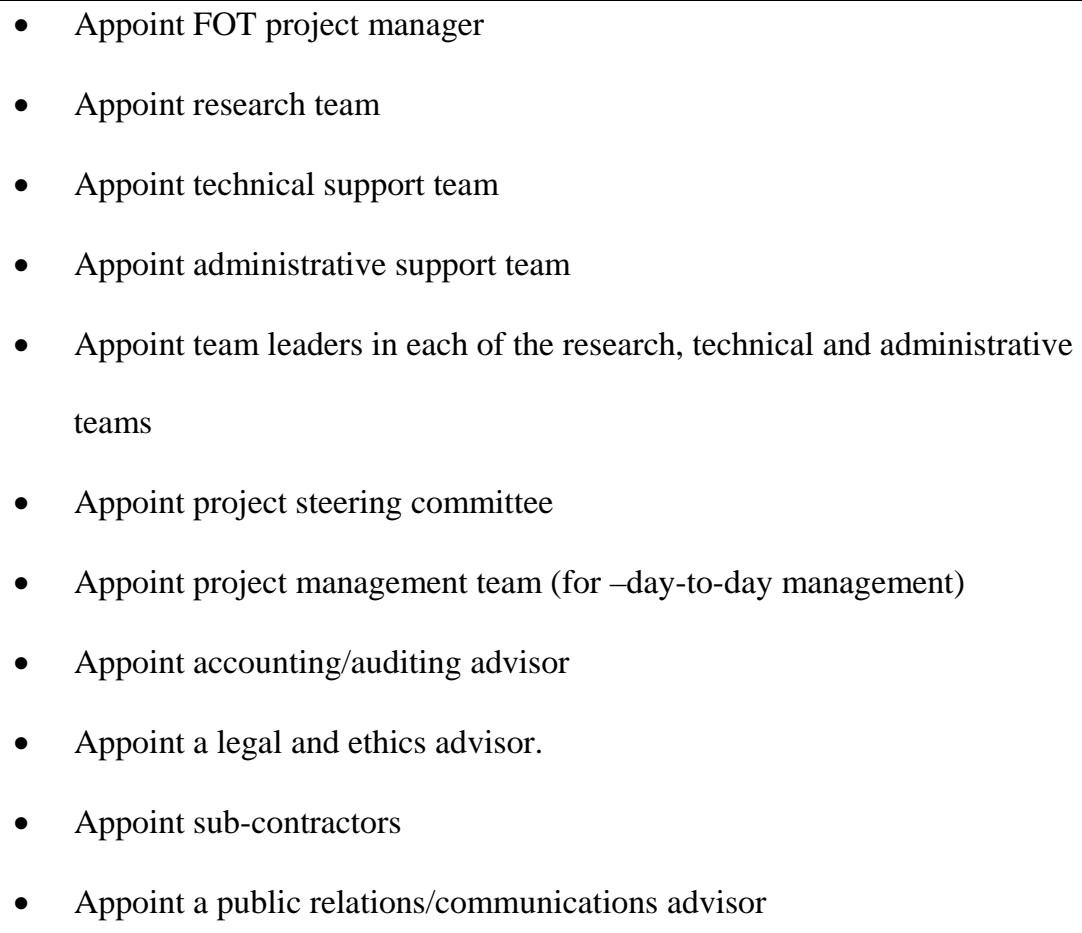 & $\begin{array}{l}\text { Appoint a multidisciplinary research team./Don’t vest critical } \\
\text { knowledge in just one person. /Appoint a standby for all key roles./ } \\
\text { Appoint, early, ethics and legal advisors./ Include “gizmo expert” on } \\
\text { top of ICT and GIS developments./ Have regular project } \\
\text { management meetings./ Choose contractors with backup } \\
\text { capacity./Ensure the FOT evaluation process is independent./ } \\
\text { Identify early a disputes resolution arbiter. }\end{array}$ \\
\hline
\end{tabular}




\begin{tabular}{|c|c|c|}
\hline Activities & Tasks & Critical Considerations (the “dos” and “don’ts”) \\
\hline & - $\quad$ Sign off on agreed research and supp & \\
\hline $\begin{array}{l}2 . \\
\text { Define aims, } \\
\text { objectives, research } \\
\text { questions and } \\
\text { hypotheses }\end{array}$ & $\begin{array}{l}\text { - } \text { Define aims and objectives of FOT, in conjunction with relevant stakeholders } \\
\text { - } \quad \text { Identify systems and functions to be tested } \\
\text { - } \quad \text { Define research questions and prioritise them } \\
\text { - } \quad \text { Formulate hypotheses to be tested, deriving from research questions } \\
\text { - Determine and resolve constraints which may prevent the aims and objectives } \\
\text { - } \quad \text { Define final aims and objectives of the FOT, and seek agreement from relevant } \\
\text { - Stakeholders. } \\
\text { Sign off on aims and objectives of FOT }\end{array}$ & $\begin{array}{l}\text { Anticipate that FOT objectives may change when administrations } \\
\text { change./Anticipate that different stakeholders may have conflicting } \\
\text { views about what they want to get out of the FOT./Define research } \\
\text { questions and prioritise them early to ensure they remain the focus of } \\
\text { the FOT. }\end{array}$ \\
\hline $\begin{array}{l}\text { Develop FOT } \\
\text { project } \\
\text { management plan }\end{array}$ & $\begin{array}{l}\text { - } \text { Define project activities, tasks and sub-tasks } \\
\text { - } \text { Decide who is accountable for completion of activities, tasks and sub-tasks } \\
\text { - } \\
\text { - Determine timelines for completion of activities, tasks and sub-tasks } \\
\text { - } \quad \text { Determine budget for project activities, tasks and timelines } \\
\text { - Implement procedures for monitoring project activities, timelines, budgets and }\end{array}$ & $\begin{array}{l}\text { Try and negotiate a 5-10\% contingency budget. /Anticipate the need } \\
\text { to consult external specialists. } / 3^{\text {rd }} \text { party vehicle fleets may change } \\
\text { during the FOT (e.g., vehicle upgrades and changes in operating } \\
\text { routes). /Develop procedural manuals to ensure that, if staff leave, } \\
\text { procedural knowledge does not go with them./Document outcomes } \\
\text { of all project meetings to record critical decisions, lessons learnt and }\end{array}$ \\
\hline
\end{tabular}




\begin{tabular}{|c|c|c|}
\hline Activities & Tasks & Critical Considerations (the “dos” and “don'ts”) \\
\hline & $\begin{array}{l}\text { resources (e. g., project management team meetings) } \\
\text { - } \quad \text { Undertake a risk assessment for the FOT and plan contingencies as required. } \\
\text { - } \quad \text { Determine sign off procedures (meetings and documents) to ensure that there } \\
\text { is sign off on all critical decisions and stages in the FOT by all relevant parties } \\
\text { - } \text { Agree on project issues which are confidential and implement mechanisms for } \\
\text { - Developuarding their confidentiality. } \\
\text { knowledge. } \\
\text { Sign off on project management plan. }\end{array}$ & $\begin{array}{l}\text { justify potential problems./Use a budgeting structure that } \\
\text { accommodates unanticipated events./Be aware that in some } \\
\text { jurisdictions project papers may be publicly accessed. }\end{array}$ \\
\hline $\begin{array}{l}4 . \\
\text { Implement } \\
\text { procedures and } \\
\text { protocols for } \\
\text { communicating } \\
\text { with stakeholders }\end{array}$ & $\begin{array}{l}\text { - } \text { Commission communications advisor to design communications plan } \\
\text { - } \quad \text { Develop and implement communications plan } \\
\text { - } \quad \text { Sign off on agreed communication protocols. }\end{array}$ & $\begin{array}{l}\text { Control communication with the media through a trained media } \\
\text { spokesperson./Build political support for the project early in the } \\
\text { FOT./ Limit media attention until data collection is complete./ } \\
\text { Budget for unsolicited media attention./Plan to have some results } \\
\text { available early in project. /Prepare a response in case of serious } \\
\text { incidents, such as crashing of a test vehicle./Anticipate direct contact } \\
\text { between the media and participant drivers./Maintain open } \\
\text { communication with all stakeholders to ensure objectives of FOT are }\end{array}$ \\
\hline
\end{tabular}




\begin{tabular}{|c|c|c|}
\hline Activities & Tasks & Critical Considerations (the “dos” and “don'ts”) \\
\hline & & $\begin{array}{l}\text { clear and that stakeholders are committed to the project./Decide in } \\
\text { advance maximum turnaround time for approvals to speak to media. }\end{array}$ \\
\hline 5. & $\begin{array}{l}\text { Become familiar with the methods, measures and procedures of previous } \\
\text { FOTs: } \\
0 \text { Attend FOTNET seminars and similar events and networking } \\
\text { activities } \\
\text { o Talk to experts who have conducted FOTs previously. } \\
\text { - Identify the performance indicators necessary to test the hypotheses derived in } \\
\text { Activity } 1 \\
\text { Select measures (objective and subjective) that allow performance indicators to } \\
\text { be derived to test the hypotheses } \\
\text { Identify the sensors and sensor requirements for obtaining the required } \\
\text { measures }\end{array}$ & $\begin{array}{l}\text { Historic data (eg., data on vehicle speeds on certain roads) is } \\
\text { necessary for baseline comparisons and Cost Benefit Analysis. /Plan } \\
\text { for direct comparisons to be made between objective data and } \\
\text { subjective data. /Employ a multidisciplinary team to develop } \\
\text { hypotheses./ Ensure all terms and phrases making up the research } \\
\text { questions and hypotheses are clearly defined and unambiguous./ } \\
\text { Don't change the study design (e.g. reduce the sample size in order } \\
\text { to save money ) if it compromises the scientific integrity of the } \\
\text { study./ Don’t assume study participants will be the only drivers of } \\
\text { the vehicles./Everyone must understand the FOT study design, so } \\
\text { that they appreciate the timing issues and the consequences of } \\
\text { changes./ Delays in one area of the program cannot always be made } \\
\text { in other areas./ When performing the sample size calculations, allow } \\
\text { for participant attrition./Anticipate that, for the business sector, the }\end{array}$ \\
\hline
\end{tabular}




\begin{tabular}{|c|c|c|}
\hline Activities & Tasks & Critical Considerations (the “dos” and “don’ts”) \\
\hline & $\begin{array}{l}\text { - Design the experimental methods, tools and procedures for testing the } \\
\text { - hypotheses } \\
\text { - Define the experimental environment in which to conduct the FOT } \\
\text { transferring, de-coding, reducing/transcribing, filtering, backing up and } \\
\text { - } \text { verifying the data. } \\
\text { - Define methods, tools and procedures for analyzing the data. } \\
\text { to ensure sufficient statistical power. } \\
\text { - Select models for estimating the potential safety, environmental and other } \\
\text { benefits of the technologies tested. } \\
\text { - Sign off on study design, methods and tools, questionnaires and associated } \\
\text { procedures. }\end{array}$ & $\begin{array}{l}\text { commercial impact of system deployment (e.g., on productivity) will } \\
\text { be important to evaluate. }\end{array}$ \\
\hline $\begin{array}{l}6 . \\
\text { Identify and } \\
\text { resolve FOT legal } \\
\text { and ethical issues }\end{array}$ & $\begin{array}{l}\text { - } \quad \text { Seek specialist advice to identify relevant legal and ethical issues } \\
\text { - } \quad \text { Resolve all legal and ethical issues that can be identified in advance } \\
\text { - } \quad \text { Create contracts and confidentiality agreements with all relevant parties (e. g., } \\
\text { car leasing organisations, suppliers, consultants, fleet managers, researchers }\end{array}$ & $\begin{array}{l}\text { Mutually agree on risks to all parties before signing contracts./Check } \\
\text { the FOT accords with ethical and legal requirements in all relevant } \\
\text { jurisdictions./ Ensure that all intellectual property issues are resolved } \\
\text { early./ Clarify the conditions under which a participant will be }\end{array}$ \\
\hline
\end{tabular}




\begin{tabular}{|c|c|c|}
\hline Activities & Tasks & Critical Considerations (the “dos” and “don'ts”) \\
\hline & $\begin{array}{l}\text { etc) for all relevant issues (e. g., data collection, provision and usage, theft, } \\
\text { insurance, privacy, duty of care, property, disposal of vehicles after the study, } \\
\text { etc) } \\
\text { - Seek ethics approval to conduct study (where required) from relevant ethics } \\
\text { committee } \\
\text { - Seek expert advice regarding liability issues and to ensure insurance provision } \\
\text { is adequate for all foreseeable eventualities } \\
\text { Ensure that vehicle's licensing requirements are adhered to in spite of the } \\
\text { modifications (implementation of data logging equipment and possibly } \\
\text { systems to be evaluated, etc.) } \\
\text { Obtain informed consent of participants before they are allowed to participate } \\
\text { in the FOT } \\
\text { Sign off on all aspects of the FOT design and procedures pertaining to legal } \\
\text { and ethical matters. }\end{array}$ & $\begin{array}{l}\text { expelled from the FOT./Clarify participant responsibilities and the } \\
\text { study's obligations to the participants./ Data use agreements should } \\
\text { allow for anonomised data to be passed to } 3^{\text {rd }} \text { parties. (NB with GPS } \\
\text { and video data it may be very difficult to guarantee anonymity)./All } \\
\text { study team members must understand the agreed response to a major } \\
\text { incident./Identify and satisfy all ethics committee requirements when } \\
\text { and if required. }\end{array}$ \\
\hline $\begin{array}{l}7 . \\
\text { Select and obtain } \\
\text { FOT Vehicles }\end{array}$ & $\begin{array}{l}\text { - Specify functional requirements, performance specifications and user } \\
\text { requirements for the test vehicles needed for the study. } \\
\text { - Specify functional requirements and performance specifications for the }\end{array}$ & $\begin{array}{l}\text { Choice of vehicles must be undertaken early in the project's } \\
\text { planning, and may impinge on the selection of participants./.Obtain } \\
\text { one or two extra vehicles to act as reserves and }\end{array}$ \\
\hline
\end{tabular}




\begin{tabular}{|c|c|c|}
\hline Activities & Tasks & Critical Considerations (the “dos” and “don'ts”) \\
\hline & $\begin{array}{l}\text { integration into vehicles of all technologies needed for the FOT (FOT } \\
\text { technologies, support technologies and data collection technologies), if these } \\
\text { are not already in the vehicles. } \\
\text { - Select test vehicles (makes and models) that meet above requirements. } \\
\text { - Purchase, lease, hire or borrow (where the driver owns the vehicle) the test } \\
\text { vehicles. } \\
\text { Sign off on selection and obtaining of test vehicles. }\end{array}$ & $\begin{array}{l}\text { demonstrators./Choose conservative model vehicles as test vehicles./ } \\
\text { Consider vehicle maintenance requirements and the dealer network } \\
\text { that is available in the FOT area. }\end{array}$ \\
\hline $\begin{array}{l}8 . \\
\text { Select and obtain } \\
\text { systems and } \\
\text { functions to be } \\
\text { evaluated during } \\
\text { FOT (if they are } \\
\text { not already } \\
\text { implemented in the } \\
\text { vehicles) }\end{array}$ & $\begin{array}{l}\text { Develop selection criteria for choosing systems and functions (OEM, } \\
\text { aftermarket and nomadic) to be tested (if the technologies to be tested have not } \\
\text { already been selected by the sponsor; see General Advice column). } \\
\text { - Use above selection criteria to select and obtain systems to be tested } \\
\text { If commercial systems do not exist, that meet the above criteria, develop } \\
\text { - } \quad \text { including for HMI and security issues). } \\
\text { infrastructure needed to support the deployment of the technologies to be }\end{array}$ & $\begin{array}{l}\text { Ensure selected technologies can interface with data-logging } \\
\text { system./Beware of costs required to adapt technologies for research } \\
\text { purposes./Public authorities will usually require considerable time to } \\
\text { provide infrastructure to support an FOT. }\end{array}$ \\
\hline
\end{tabular}




\begin{tabular}{|c|c|c|}
\hline Activities & Tasks & Critical Considerations (the “dos” and “don’ts”) \\
\hline & $\begin{array}{l}\text { tested (e. g. digital maps, roadside beacons). } \\
\text { - Source infrastructure that meets the above functional requirements and } \\
\text { - Whecifications. } \\
\text { infrastructure that meets the above functional requirements and performance } \\
\text { - } \text { If approprifications. } \\
\text { of systems and supporting infrastructure. } \\
\text { If appropriate select preferred tenderers, negotiate contracts and award } \\
\text { contracts. } \\
\text { Decide what will be done with the test vehicles, and the equipment in them, } \\
\text { once the FOT has been completed. } \\
\text { Sign off on selection and obtaining of technologies to be evaluated during the } \\
\text { FOT }\end{array}$ & \\
\hline $\begin{array}{l}9 . \\
\text { Select and obtain } \\
\text { data collection and }\end{array}$ & $\begin{array}{l}\text { - Specify data to be logged (measures and sampling rate) } \\
\text { - Specify functional requirements and performance specifications for systems } \\
\text { for collecting and transferring the data to be logged. }\end{array}$ & $\begin{array}{l}\text { Plan for software upgrades and sensor recalibration during the FOT } \\
\text { - preferably remotely./Make sure in-vehicle data logging systems } \\
\text { are unobtrusive, safe, secure and accessible to enable routine }\end{array}$ \\
\hline
\end{tabular}




\begin{tabular}{|c|c|c|}
\hline Activities & Tasks & Critical Considerations (the “dos” and “don’ts”) \\
\hline $\begin{array}{l}\text { transfer systems for } \\
\text { FOT vehicles }\end{array}$ & $\begin{array}{l}\text { - Source, purchase and/or develop systems for logging and transferring the data } \\
\text { that meet the above functional requirements and performance specifications. } \\
\text { - Sign off on selection and obtaining of data collection and transfer system for } \\
\text { test vehicles. }\end{array}$ & $\begin{array}{l}\text { repairs./Keep a stock of spares for critical items (eg flash memory } \\
\text { cards)./Minimise driver involvement in data download from test } \\
\text { vehicles./Test system and logger boot-up time must be fast enough } \\
\text { to prevent data loss at the beginning of each trip./Ensure that a } \\
\text { common time stamp is used for all recorded data sources./Regular } \\
\text { confirmation that data collection is proceeding correctly is essential./ } \\
\text { Anticipate ad-hoc and post-hoc interrogation of raw data files to } \\
\text { answer additional questions. }\end{array}$ \\
\hline $\begin{array}{l}10 . \\
\text { Select and obtain } \\
\text { support systems for } \\
\text { FOT vehicles }\end{array}$ & $\begin{array}{l}\text { - Define the support systems needed (see General Advice Column) } \\
\text { - Develop functional requirements and performance specifications for systems } \\
\text { needed to support the study } \\
\text { - Where appropriate, develop functional requirements and performance } \\
\text { specifications for the HMI, to ensure that the HMI for support systems is safe } \\
\text { and user-friendly } \\
\text { - Source, purchase and/or develop support systems that meet above functional } \\
\text { requirements and performance specifications } \\
\text { Sign off on selection and obtaining of support systems for test vehicles. }\end{array}$ & $\begin{array}{l}\text { Ideally support systems should be capable of remote operation to } \\
\text { allow, for example, remote system re-boot./Anticipate data analysis } \\
\text { requirements before specifying data to be logged (e. g., rates and } \\
\text { resolution)./Ensure that missing data are uniquely indicated in data } \\
\text { files./Log more parameters if performance of the data logging } \\
\text { system or storage capacity are not affected. }\end{array}$ \\
\hline
\end{tabular}




\begin{tabular}{|c|c|c|}
\hline ies & Tasks & Critical Considerations (the “dos” and “don’ts”) \\
\hline $\begin{array}{l}11 . \\
\text { Equip FOT } \\
\text { vehicles with all } \\
\text { technologies }\end{array}$ & 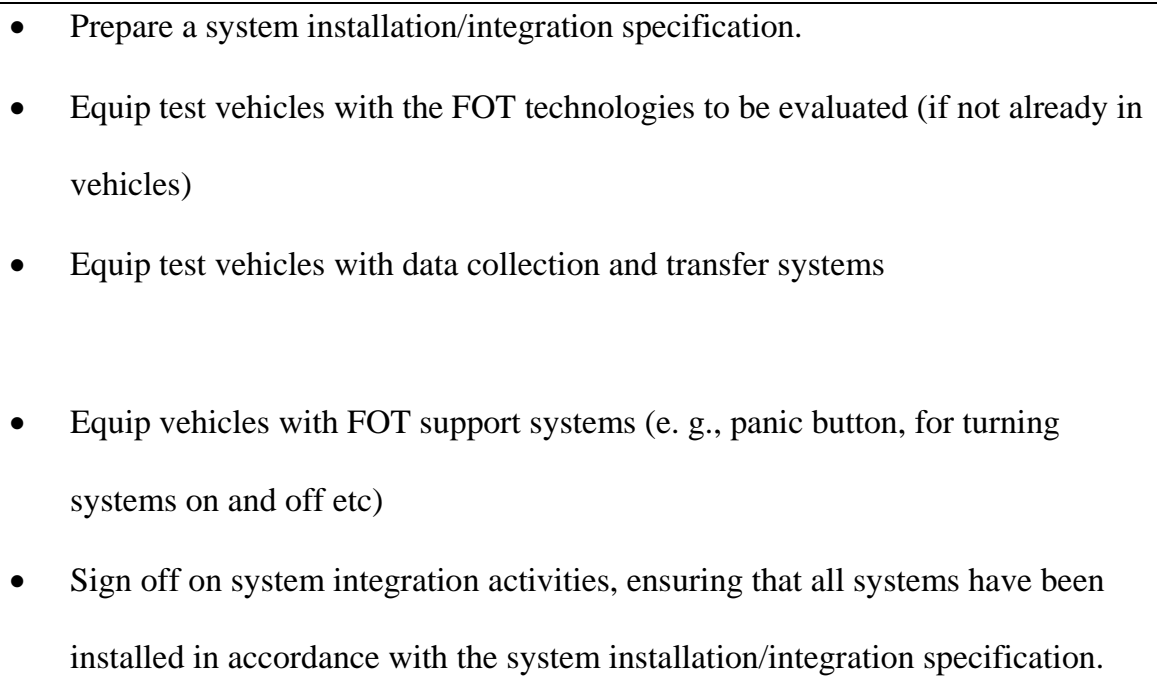 & $\begin{array}{l}\text { FOT-related in-car computer must have sufficient processing power } \\
\text { to avoid delays. / All systems (FOT, data collection and support) } \\
\text { must operate identically across test vehicles./Try to make all } \\
\text { adaptations to test vehicles invisible to reduce the likelihood of theft } \\
\text { or behaviour modification by other drivers./Allow a burn in period } \\
\text { (around } 1000 \mathrm{~km} \text { ) so that vehicle faults that could disrupt the FOT } \\
\text { are resolved./Create protocols that standardise the procedure for } \\
\text { installing all in-vehicle equipment. }\end{array}$ \\
\hline $\begin{array}{l}12 . \\
\text { Design and } \\
\text { implement driver } \\
\text { feedback and } \\
\text { reporting systems }\end{array}$ & $\begin{array}{l}\text { - Design, develop and implement systems and procedures to allow drivers to } \\
\text { report technical problems in a timely manner. } \\
\text { - Design, develop and implement systems and procedures to allow drivers to } \\
\text { provide feedback to researchers, in real time or retrospectively (e. g., usability } \\
\text { problems, opinions of systems, confirmation that systems are operating as } \\
\text { - Design, develop and implement systems and procedures that allow researchers } \\
\text { to monitor participant progress (e. g., to ensure they are adhering to study }\end{array}$ & $\begin{array}{l}\text { Implement driver trip diaries if necessary./Implement a timetable for } \\
\text { collection of qualitative data./ Note - drivers may not complete } \\
\text { diaries or attend interviews./Appoint a driver liaison person as a } \\
\text { single point of contact./Ensure project team is responsive to } \\
\text { emergencies and incidents on a } 24 / 7 \text { basis./Know when participants } \\
\text { are going on holiday/ or not driving./Record all reported problems } \\
\text { and document them./Document feedback and reporting procedures in } \\
\text { a reference manual./Decide how to collect fuel consumption }\end{array}$ \\
\hline
\end{tabular}




\begin{tabular}{|c|c|c|}
\hline Activities & Tasks & Critical Considerations (the “dos” and “don'ts”) \\
\hline & $\begin{array}{l}\text { requirements). } \\
\text { - Sign off on implementation of driver feedback and reporting systems and } \\
\text { procedures }\end{array}$ & $\begin{array}{l}\text { information/Appreciate that drivers will not always use fuel cards, } \\
\text { return fuel dockets or fill in the fuel logbooks. }\end{array}$ \\
\hline $\begin{array}{l}13 . \\
\text { Select, obtain and } \\
\text { implement standard } \\
\text { relational database } \\
\text { for storing FOT } \\
\text { data }\end{array}$ & $\begin{array}{l}\text { - Design, develop and implement a database for storing data logged from the test } \\
\text { vehicles } \\
\text { - Design, develop and implement a database for storing the subjective data } \\
\text { collected from participants (e. g., from questionnaires, from focus groups, from } \\
\text { feedback lines etc) } \\
\text { - } \quad \text { Sevelop data navigation and visualization tools } \\
\text { Sign on database for storing FOT data. }\end{array}$ & $\begin{array}{l}\text { Ensure a system evaluator reviews the database architecture prior to } \\
\text { FOT launch./Make copies of raw data, reduced raw data and all } \\
\text { processed data files, and store away from primary data store./Use } \\
\text { industry standard relational database to store data./Ensure no } \\
\text { unauthorized access to database./Design database to reduce need for } \\
\text { post-collection manipulation./Decide early how to manage post- } \\
\text { project data. Key issues are: What happens to data when project } \\
\text { ends? Who has data usage rights? Who can access it? Who pays for } \\
\text { possible storage?/ Where data is taken off-line, what meta data } \\
\text { should be kept, and how? }\end{array}$ \\
\hline $\begin{array}{l}14 . \\
\text { Test all } \\
\text { technologies } \\
\text { against functional }\end{array}$ & $\begin{array}{l}\text { - Develop “acceptance testing” protocols (see comment column). } \\
\text { - Test the technologies for acceptance, using the acceptance testing protocol. } \\
\text { - Develop a usability test plan for the purpose of assessing the systems for } \\
\text { usability. }\end{array}$ & $\begin{array}{l}\text { Don’t sign off on previous activities until all technologies have been } \\
\text { tested and refined./ Don’t let systems drain the battery when the } \\
\text { engine is off./ Legally secure all retrofitted systems./ Implement } \\
\text { quality assurance programs for sub-contractors./ Beware - system }\end{array}$ \\
\hline
\end{tabular}




\begin{tabular}{|c|c|c|}
\hline Activities & Tasks & Critical Considerations (the “dos” and “don'ts”) \\
\hline $\begin{array}{l}\text { requirements and } \\
\text { performance } \\
\text { specifications }\end{array}$ & $\begin{array}{l}\text { - Conduct usability testing, using the usability testing plan, to ensure systems are } \\
\text { - } \text { user-friendly and that the systems meet all usability assessment criteria. } \\
\text { - } \quad \text { Assess systems, using the ergonomic checklist, to ensure that they meet all } \\
\text { - } \text { relevant criteria. } \\
\text { Assess vehicles against relevant certification procedures to ensure that vehicles } \\
\text { are safe, roadworthy and comply with all relevant National, State and Territory } \\
\text { - } \text { laws, treaties and other protocols. } \\
\text { Ensure that all vehicle modifications that affect primary safety are signed off } \\
\text { by a competent engineer or appropriate testing authority. } \\
\text { Rectify all technical, usability, ergonomic and certification issues where } \\
\text { deficiencies are noted. }\end{array}$ & $\begin{array}{l}\text { clocks can drift significantly./ Ensure that alignment and calibration } \\
\text { of sensors is maintained and tested in all potential weather } \\
\text { conditions./Beware -system components may become corrupted over } \\
\text { time with continuous use./Create an installation manual for all } \\
\text { vehicle modification procedures./Obtain waivers or special licenses } \\
\text { for equipment that is non-compliant (e.g., radars outside legal } \\
\text { bandwidths)./ Employ a competent authority to test vehicle } \\
\text { modifications for safety (e. g. proper deployment of airbags } \\
\text { following modification to vehicle interiors)/ Beware - some systems } \\
\text { (e. g., displays) that are not OEM-installed may fail in automotive } \\
\text { environments./ Test for radio frequency (RF) interference effects./ } \\
\text { Ensure normal vehicle systems (e. g., remote locking) are not } \\
\text { affected by installed equipment/.Ensure sufficient computer “grunt” } \\
\text { to power all relevant systems./Assess the HMI for all systems prior } \\
\text { to deployment to identify problems that may explain or confound } \\
\text { system effects./Provide a written statement for participants to keep in } \\
\text { vehicles to confirm their participation in the study and explain }\end{array}$ \\
\hline
\end{tabular}




\begin{tabular}{|c|c|c|}
\hline Activities & Tasks & Critical Considerations (the “dos” and “don’ts”) \\
\hline & & $\begin{array}{l}\text { vehicle modifications./Anticipate that resolving technical, usability, } \\
\text { ergonomic, and certification issues takes a lot of time. }\end{array}$ \\
\hline $\begin{array}{l}15 . \\
\text { Develop FOT } \\
\text { recruitment } \\
\text { strategy and } \\
\text { materials }\end{array}$ & $\begin{array}{l}\text { - Develop recruitment strategy, including driver entry and exit requirements and } \\
\text { procedures. } \\
\text { - } \quad \text { Develop recruitment materials and procedures } \\
\text { - Sign off on recruitment strategy, materials and procedures. }\end{array}$ & $\begin{array}{l}\text { Assume an attrition rate of } 10 \text { to } 15 \% \text { when using company drivers./ } \\
\text { Beware -company drivers may change jobs within a company, which } \\
\text { may affect annual mileage rates./If fleet drivers are recruited via a } \\
\text { fleet owner or manager, get buy-in also from individual drivers./ } \\
\text { Beware - it is harder to recruit women than men when using } \\
\text { company drivers./ Select drivers who do not pose a risk to } \\
\text { themselves, the project or others, but without biasing the participant } \\
\text { sample./ Beware -company drivers are harder to recruit than private } \\
\text { drivers./Beware - some commercial operations may have driver turn- } \\
\text { over rates approaching } 100 \% \text { per annum. }\end{array}$ \\
\hline $\begin{array}{l}16 . \\
\text { Develop FOT } \\
\text { driver training and } \\
\text { briefing materials }\end{array}$ & $\begin{array}{l}\text { - Conduct training needs analysis (TNA) to identify training requirements (if } \\
\text { appropriate) } \\
\text { - Design and develop driver briefing and training materials, based on outputs of } \\
\text { the TNA. } \\
\text { - Design and develop briefing materials for participating car/truck fleet }\end{array}$ & $\begin{array}{l}\text { Design training and briefing protocols so as not to confound system } \\
\text { effects./ Ensure all drivers understand existing in-vehicle systems as } \\
\text { well as test systems, especially if use of them is required as part of a } \\
\text { baseline comparison./Beware - development briefing and training } \\
\text { materials is very time consuming./ Anticipate that some car }\end{array}$ \\
\hline
\end{tabular}




\begin{tabular}{|c|c|c|}
\hline Activities & Tasks & Critical Considerations (the “dos” and “don’ts”) \\
\hline & $\begin{array}{l}\text { managers (if appropriate) } \\
\text { - } \quad \text { Design and develop FOT system(s) user manual (if appropriate) } \\
\text { training to the FOT participants } \\
\text { - Sign off on driver training and driver (and company) briefing materials and } \\
\text { delivery processes. }\end{array}$ & $\begin{array}{l}\text { manufacturers will not wish participating drivers to receive any } \\
\text { training. In such cases, "structured familiarisation” may be } \\
\text { acceptable./ Provide drivers with a mini-systems operating manual } \\
\text { and give them materials that can be taken away after briefing } \\
\text { sessions as memory joggers for important information. }\end{array}$ \\
\hline $\begin{array}{l}17 . \\
\text { Pilot test FOT } \\
\text { equipment, } \\
\text { methods and } \\
\text { procedures }\end{array}$ & $\begin{array}{l}\text { - Develop protocol for pilot testing FOT equipment, methods, procedures and } \\
\text { materials (including training, briefing materials and data collection, } \\
\text { downloading and analysis procedures) } \\
\text { - } \quad \text { Recruit, brief and train pilot participants } \\
\text { Deploy a small sample of FOT vehicles under a representative range of driving } \\
\text { conditions that will be experienced in the FOT, as per the pilot testing } \\
\text { protocol. } \\
\text { Fine tune FOT vehicles and technologies, systems, procedures and protocols, } \\
\text { as required, on the basis of the pilot data yielded. } \\
\text { Sign off on pilot testing. }\end{array}$ & $\begin{array}{l}\text { Undertake a 'full dress rehearsal' of the FOT on a scale that is } \\
\text { smaller than the FOT but big enough to properly test all systems, } \\
\text { procedures, and equipment. Do not truncate pilot testing - it's } \\
\text { critical./Use pilot testing also to estimate time required to complete } \\
\text { activities, to inform budgeting./Ensure that the routes used in pilot } \\
\text { studies maximise the likelihood of critical situations of relevance to } \\
\text { the FOT./Add independent monitoring systems to pilot vehicles to } \\
\text { ensure the validity of data derived from sensors./ Listen to drivers as } \\
\text { well as owners of vehicle fleets - their ideas are likely to be } \\
\text { different. }\end{array}$ \\
\hline 18. & - $\quad$ Ensure that all sign offs have occurred for previous activities. & Plan for, driver 'dropout'— over-sample./ Develop protocols for \\
\hline
\end{tabular}




\begin{tabular}{|c|c|c|}
\hline Activities & Tasks & Critical Considerations (the “dos” and “don'ts”) \\
\hline Run the FOT & 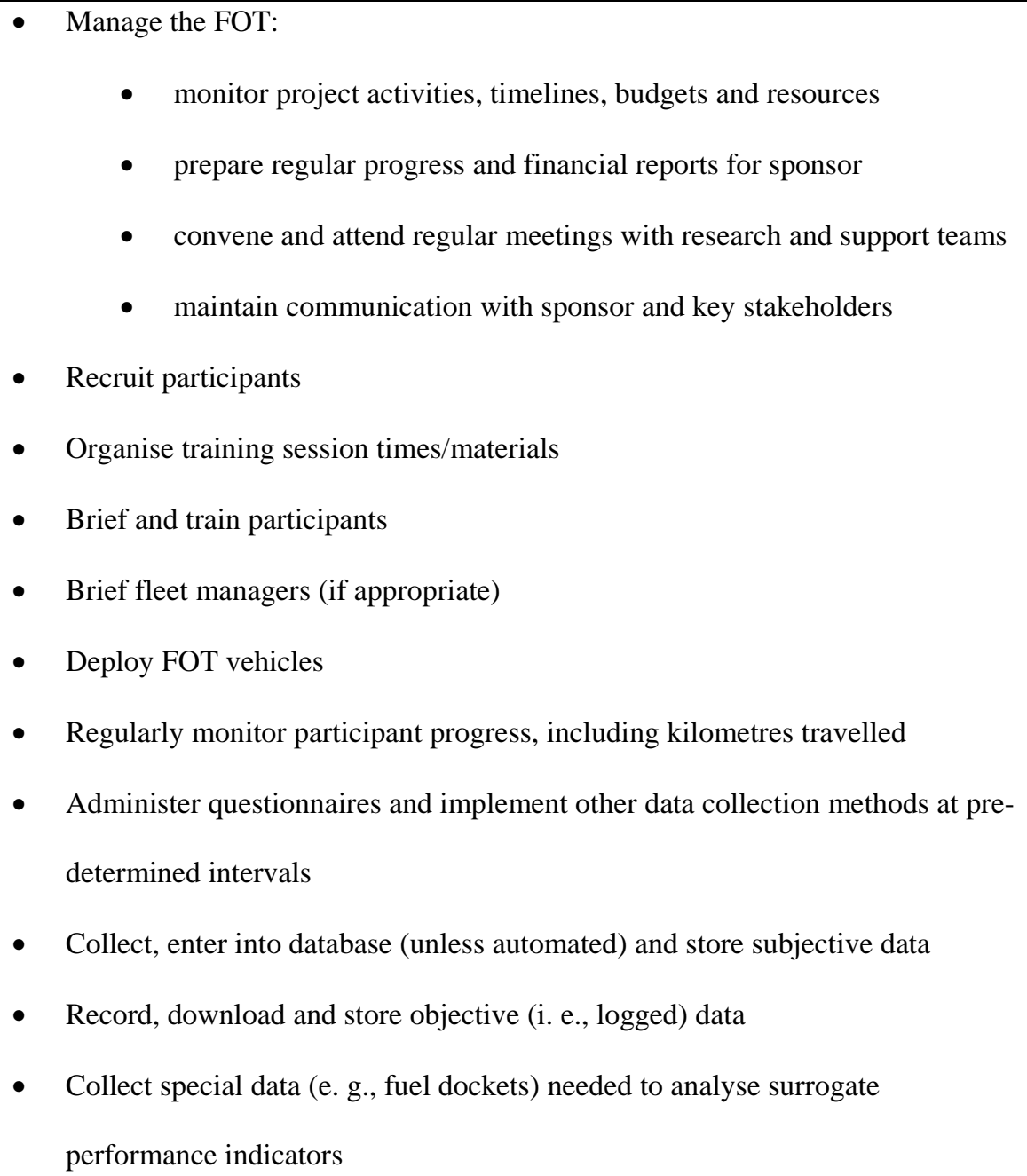 & $\begin{array}{l}\text { responding quickly to drivers with technical and other } \\
\text { problems./Anticipate problems that may increase the drop out } \\
\text { rate./Ensure that data is being properly recorded and } \\
\text { downloaded./Adhere to calibration procedures to ensure accuracy of } \\
\text { measurements and sensors over time and help prevent data drift } \\
\text { problems./ If the number of kilometres driven by drivers is being } \\
\text { controlled for, conduct regular calibration checks of cumulative } \\
\text { distance traveled./Check logged data as soon as received to verify } \\
\text { accuracy and completeness of data, and verify kilometres } \\
\text { traveled./Monitor and record critical factors that could impact on } \\
\text { measured outcomes (e. g., changes in Police enforcement } \\
\text { strategies)./Give sponsors early warning of potential problems that } \\
\text { could compromise the study, or increase the budget./ Encourage } \\
\text { participants to report quickly any technical problems./ Regularly } \\
\text { check that all systems in test vehicles are functioning as required./ } \\
\text { Drivers need regular reminding and follow-up - don't forget./ Don’t } \\
\text { forget to replace full flash memory cards, or other manual storage }\end{array}$ \\
\hline
\end{tabular}




\begin{tabular}{|c|c|c|}
\hline Activities & Tasks & Critical Considerations (the “dos” and “don'ts”) \\
\hline & $\begin{array}{l}\text { - } \text { Monitor for, collect and document data on technical problems and user } \\
\text { - } \quad \text { Coedback } \\
\text { - } \quad \text { Repaiving and re-deploy vehicles (as required) } \\
\text { - } \quad \text { Routinely ensure vehicles and vehicle systems are properly maintained and } \\
\text { - } \quad \text { Report dangerous driving behaviours (if legally required) } \\
\text { - Conduct exit interviews with drivers and fleet managers } \\
\text { - } \quad \text { Remove systems and equipment from private vehicles (if used) } \\
\text { Sign off on completion of this activity of the FOT. }\end{array}$ & $\begin{array}{l}\text { devices, with empty ones./ If legally required, report to appropriate } \\
\text { authorities dangerous driving by test drivers./ Beware - trailers, bike } \\
\text { racks and other accessories may adversely affect the operation of } \\
\text { some FOT systems./ Minimise interference to commercial operations } \\
\text { during FOTS./ Make sure fleet managers are, and remain, motivated } \\
\text { and engaged./ Allow sufficient time for data entry which has to be } \\
\text { done manually- and don't leave it to the end./Develop a system for } \\
\text { basic inventory management for FOTs with more than a few } \\
\text { vehicles. }\end{array}$ \\
\hline $\begin{array}{l}19 . \\
\text { Analyse FOT data }\end{array}$ & $\begin{array}{l}\text { - Develop a data analysis plan } \\
\text { - Analyse objective (i. e., logged and recorded data) } \\
\text { - Analyse subjective data (i. e., data obtained from interviews, questionnaires, } \\
\text { - } \text { focus groups, hotlines, etc) } \\
\text { - Draw conclusions with respect to the hypotheses generated for the FOT }\end{array}$ & $\begin{array}{l}\text { Anticipate the demand for study findings (eg trends) early in the } \\
\text { project./ Anticipate the need to perform supplementary analyses for } \\
\text { the sponsor, which may be expensive and not budgeted for./ Run } \\
\text { "reality checks" on the data, to be sure that they are “clean”./ If data } \\
\text { is reduced or aggregated, keep a copy of un-aggregated data./Ensure }\end{array}$ \\
\hline
\end{tabular}




\begin{tabular}{|c|c|c|}
\hline Activities & Tasks & Critical Considerations (the “dos” and “don'ts”) \\
\hline & - $\quad$ Sign off on completion of all required analyses & $\begin{array}{l}\text { that all data analysts have used the test vehicles and understand the } \\
\text { circumstances in which data was/or is collected./Brief all team } \\
\text { members who handle participant data on data privacy issues./Work } \\
\text { out how best to filter logged data and deal with missing data. }\end{array}$ \\
\hline $\begin{array}{l}20 . \\
\text { Write minutes and } \\
\text { reports }\end{array}$ & $\begin{array}{l}\text { - Write minutes of regular project management team meetings } \\
\text { - Write regular minutes of Project Steering Committee meetings } \\
\text { - Write quarterly progress reports for the sponsor(s) } \\
\text { - Write the draft FOT report } \\
\text { - } \quad \text { Cond the draft FOT report to relevant stakeholders and peers for peer-review } 1 \text { or } 2 \text { meetings to discuss feedback with sponsor/peers } \\
\text { - } \quad \text { Incorporate feedback and write final report. } \\
\text { - } \text { Deliver final report to sponsor(s) }\end{array}$ & $\begin{array}{l}\text { Document problems, solutions and lessons learnt in progress } \\
\text { reports./Agree on a reasonable time for sponsor to review } \\
\text { reports./Consider peer reviewing of major deliverables./Document } \\
\text { all lessons learnt in the final FOT report./Include in the final report } \\
\text { practical recommendations for wider scale deployment of systems } \\
\text { found to be effective, and for fine-tuning of those with potential to } \\
\text { be more effective./ Document in the final report a plan for } \\
\text { implementing the recommendations deriving from the FOT./FOTs } \\
\text { have long lifecycles - write separate reports on each critical stage to } \\
\text { ensure nothing important is forgotten. }\end{array}$ \\
\hline 21. & $\begin{array}{l}\text { - Send regular project reports to the sponsor } \\
\text { - Disseminate preliminary and final findings at seminars, conferences and } \\
\text { special events }\end{array}$ & $\begin{array}{l}\text { Disseminate the findings in accordance with the communications } \\
\text { plan, and other contractual obligations./Agree on what can and } \\
\text { cannot be disseminated and said at different points in the study. }\end{array}$ \\
\hline
\end{tabular}




\begin{tabular}{|c|c|c|}
\hline Activities & Tasks & Critical Considerations (the “dos” and “don'ts”) \\
\hline FOT findings & 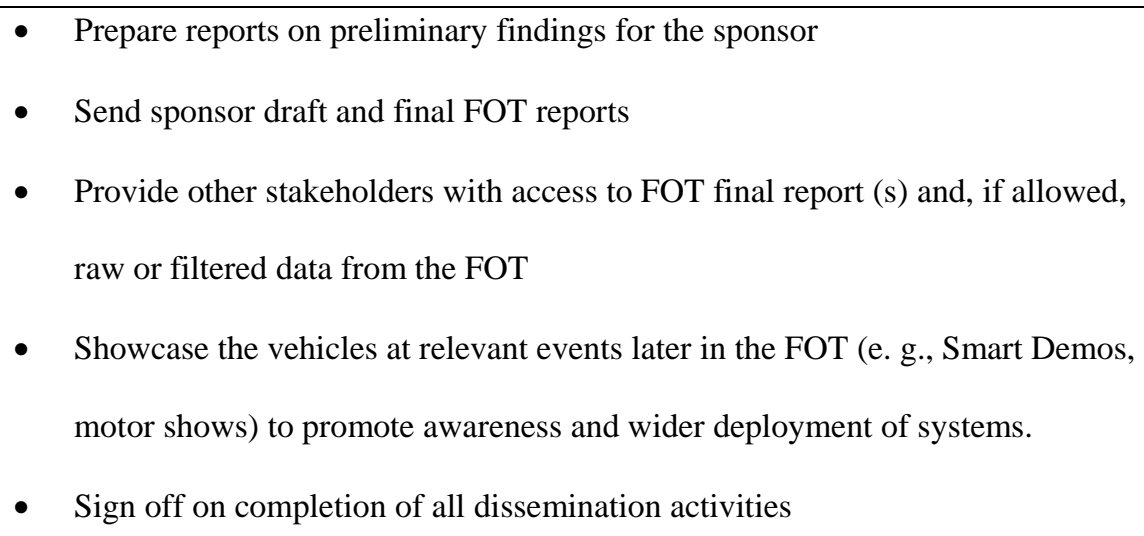 & $\begin{array}{l}\text { /Seek necessary permissions before divulging FOT findings to any } \\
\text { third party./Allocate sufficient budget for printing, if } \\
\text { required./Prepare a } 1 \text { or } 2 \text { page synopsis of the study outcomes that } \\
\text { can be read and easily digested by politicians, chief executives and } \\
\text { relevant others in positions of authority./Agree in advance who is } \\
\text { empowered to release and comment on results. }\end{array}$ \\
\hline $\begin{array}{l}22 . \\
\text { Decommission the } \\
\text { FOT }\end{array}$ & $\begin{array}{l}\text { - Conduct de-briefing interviews with participants to elicit feedback on the FOT } \\
\text { that can be used to improve future FOTs. } \\
\text { - } \quad \text { Dispose of test vehicles which are no longer needed (if vehicles are not } \\
\text { privately owned). } \\
\text { - } \quad \text { Retrieve installed data logging equipment (if vehicles are privately owned) }\end{array}$ & $\begin{array}{l}\text { Ensure that participants return relevant items at the end of the study } \\
\text { and perform other required activities to decommission the FOT } \\
\text { vehicles (e.g., disconnect power to support systems)./Keep one } \\
\text { vehicle until all data analyses are complete./Consider providing } \\
\text { public access to FOT databases, where ethically allowed, that } \\
\text { enables others to use the data for other research purposes after the } \\
\text { FOT. / Don't lose momentum at the end of the FOT - lobby } \\
\text { stakeholders to ensure that there is commitment to implementing the } \\
\text { recommendations of the FOT. }\end{array}$ \\
\hline
\end{tabular}

